Verkaik, R., Busch, M., Koeneman, T., Berg, R. van den, Spreeuwenberg, P., Francke, A.L. Guided imagery in people with fibromyalgia: A randomized controlled trial of effects on pain, functional status and self-efficacy. Journal of Health Psychology: 2014, 19(5), 678-688

\begin{tabular}{|l|l|}
\hline $\begin{array}{l}\text { Postprint } \\
\text { Version }\end{array}$ & 1.0 \\
\hline Journal website & http://hpq.sagepub.com/content/early/2013/03/21/1359105313477673.long \\
\hline Pubmed link & $\underline{\text { http://www.ncbi.nlm.nih.gov/pubmed/23520350 }}$ \\
\hline DOI & $10.1177 / 1359105313477673$ \\
\hline
\end{tabular}

This is a NIVEL certified Post Print, more info at http://www.nivel.eu

\title{
Guided imagery in people with fibromyalgia: A randomized controlled trial of effects on pain, functional status and self-efficacy
}

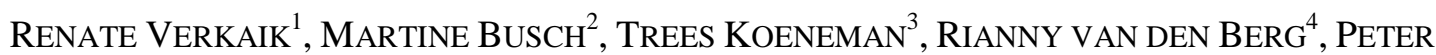 \\ SPREEUWENBERG ${ }^{1}$ AND ANNEKE L FRANCKE ${ }^{1}$
}

\footnotetext{
${ }^{1}$ Netherlands Institute for Health Services Research NIVEL, The Netherlands

${ }^{2}$ Van Praag Instituut, The Netherlands

${ }^{3}$ Aveant, The Netherlands

${ }^{4}$ F.E.S., The Netherlands
}

\begin{abstract}
Studies on the effects of guided imagery in patients with fibromyalgia show varying results. This randomized controlled trial $(n=65)$ aims to give more insight into the effects on pain, functional status, and self-efficacy. Daily pain was assessed with a pain diary using a Visual Analogue Scale. Functional status and self-efficacy were measured at pretest, posttest, and follow-up using the Fibromyalgia Impact Questionnaire and the Chronic Pain Self-Efficacy Scale. No effects of guided imagery could be established. Explanations for the diverging results between studies might be found in the content of the exercises, length of the intervention period, and background of participants.
\end{abstract}

Fibromyalgia (FM) is a complex rheumatic disorder that affects up to 5 percent of the general population worldwide. In addition to chronic widespread pain, patients often experience fatigue, disturbed sleep, stiffness, reduced functioning, and cognitive problems. The underlying cause of FM is still unknown. In a recent literature review, McCarberg (2012) found that current studies indicate that abnormal sensory and pain processing is a key factor in FM (Bradley, 2009; Nielsen and Henriksson, 2007; Staud, 2006). Patients with FM often exhibit heightened sensitivity to painful stimuli or painful reactions to nonpainful stimuli (Stahl, 2009). Results from a number of studies suggest that genetic factors are involved in the etiology of FM (Ablin et al., 2008; Buskila et al., 2007; Williams and Clauw, 2009). Additionally, environmental stressors are likely to be involved in the development of FM, for example, physical trauma, certain infections, and emotional stress (Ablin et 
Verkaik, R., Busch, M., Koeneman, T., Berg, R. van den, Spreeuwenberg, P., Francke, A.L. Guided imagery in people with fibromyalgia: A randomized controlled trial of effects on pain, functional status and self-efficacy. Journal of Health Psychology: 2014, 19(5), 678-688

al., 2008; Williams and Clauw, 2009). Because the causes of FM are unknown, its treatment often focuses on pain management, improving sleep or relieving depression. According to the McCarberg's (2012) review, many patients with FM may benefit from a combination of pharmacological and nonpharmacological therapies. Nonpharmacological therapies for which some evidence exists that they have a positive influence on symptoms of FM are cognitive behavioral therapy and patient education. A therapy for which the scientific results are inconclusive is guided imagery (GI). According to Menzies et al. (2004, 2006), imagery has been defined as a dynamic, psychophysiological process in which a person imagines, and experiences, an internal reality in the absence of external stimuli. A person who uses imagery may experience an affective, behavioral, or physiologic response without a real stimulus. In this way, mental imagery may be used to alter one's physiologic process, mental state, or behavior (Eller, 1999; Lewith et al., 1996; Menzies and Taylor, 2004). Bradley and McKendree-Smith (2002) describe a neuromatrix that constructs a framework for understanding the interaction between physiologic mechanisms and psychosocial factors in the development and maintenance of chronic pain. This construct suggests that behavioral and psychological interventions may alter the pain experience primarily through their effects on emotional states and cognitive processes (Figure 1).

It is hypothesized that GI influences emotional state, attention, and cognitive processes, which subsequently influences pain experiences and behavior of persons with persistent pain. At the time of the current study, three studies had been conducted into the effects of GI on pain in FM, with varying results. The first two studies were performed by Fors et al. (2000, 2002). In both studies, significant positive effects were shown on experienced pain. The third study by Menzies et al. (2006) was able to show positive effects of GI on functional status and self-efficacy, but not on experienced pain. We assumed that the effects on pain perception in the study by Menzies et al. (2006) were present, but could not be shown due to measurement problems. Menzies et al. (2006) used the Short-Form McGill Pain Questionnaire (SF-MPG) at pretest, posttest, and follow-up to assess changes in experienced pain, which is probably a less sensitive measure than the Visual Analogue Scale (VAS) that Fors et al. (2002) used on a daily basis. We also assumed that the effects on pain, functional status, and self-efficacy could already be shown within a period of 4 weeks, comparable with the intervention period in the study by Fors et al. We therefore conducted a study comparable with that by Menzies et al. (2006), with the duration of Fors et al.'s (2002) study, and replaced the SF-MPG by daily pain measures with a VAS in order to assess the effects of GI on pain level, functional status, and self-efficacy in persons with FM.

\section{METHODS}

\section{Design}

The study is a randomized clinical trial on the effects of GI on pain, functional status, and self-efficacy in patients with FM. The intervention group received two 1.5-hour group sessions, including group discussion, instruction about GI as well as a compact disc with GI exercises. The intervention group was asked to perform one or two GI exercises per day over 4 weeks. The duration of the intervention period was comparable with the duration in the study by Fors et al. (2002). The control group 
Verkaik, R., Busch, M., Koeneman, T., Berg, R. van den, Spreeuwenberg, P., Francke, A.L. Guided imagery in people with fibromyalgia: A randomized controlled trial of effects on pain, functional status and self-efficacy. Journal of Health Psychology: 2014, 19(5), 678-688

received two 1.5-hour group sessions, including group discussion. Pain and medication use were measured daily in a pain diary. For measuring functional status and self-efficacy, there were three measuring times:

1. Pretest (just before the first group session);

2. Posttest (at the beginning of the second group session);

3. Follow-up (6 weeks after the second group session).

\section{[FIGURE 1]}

Data collection took place between February 2010 and January 2011. The study was approved by the Medical Ethics Committee of the University Medical Center Utrecht (UMCU), protocol 09-187. The study was registered in the Dutch Trial Register, NTR2172.

\section{Sample size}

The sample size of patients with FM was calculated using Cohen's $\mathrm{d}(\mathrm{d}=$ (meanX_experimental - meanX_control)/S_pooled), using the mean reduction of pain of $20.4 \mathrm{~mm}$ in the study by Fors et al. (2002) on a VAS from 0 to $100 \mathrm{~mm}$. The standard deviation (SD) in the experimental group on this scale in this study was 24.0 $\mathrm{mm}$ at baseline. We expect the SD in our group to be similar to that in the study by Fors et al. (2002), because participants in both studies are recruited by associations of patients with FM and have a FM diagnosis from a physician using the American College of Rheumatology 1990 criteria for the classification of FM. Furthermore, we use an estimated correlation of 0.7 between pretest and posttest. This means that 27 participants are needed in the GI group and the same number in the control group, meaning 54 patients in total (Cohen, 1988).

\section{Participants}

The study sample $(\mathrm{N}=65)$ was recruited in several ways: by notices on the website of the Dutch association for patients with FM, by sending e-mails to all members, and via notices in local newspapers. Patients who were interested in participating received an information letter, containing information about the study, the eligibility criteria, and their rights once they agreed to participate. Together with the information letter, patients received an overview of the dates on which the group sessions would take place and an informed consent form.

Eligibility criteria were $\leq 6$ years since the diagnosis of FM, made by a physician (rheumatologist or general practitioner), being able to travel and to sit for 1.5 hours and having sufficient hearing. Self-reported diagnosis of FM was confirmed by the participant's rheumatologist or general practitioner by asking them for a copy of the original diagnosis. (In The Netherlands, the American College of Rheumatology 1990 criteria for the classification of FM are used as the golden standard to diagnose FM, both by general practitioners and by rheumatologists. Exclusion criterion was the presence of a psychiatric illness (self-reported).

\section{Group randomization}

Patients who wanted to participate were asked to fill out the informed consent form and to indicate whether they wanted to attend group sessions in the afternoon or in the evening, and on which dates they would not be able to participate. In this way, four groups of 6-12 persons could be formed. After the groups were formed (based 
Verkaik, R., Busch, M., Koeneman, T., Berg, R. van den, Spreeuwenberg, P., Francke, A.L. Guided imagery in people with fibromyalgia: A randomized controlled trial of effects on pain, functional status and self-efficacy. Journal of Health Psychology: 2014, 19(5), 678-688

on preferences for evening or afternoon sessions on certain days), a secretary not involved in the study randomly drew lots with the number of the groups (1-4) from a sealed envelope.

The first group numbers that were drawn were assigned to the experimental condition, and the last two numbers were assigned to the control condition. About half $(n=27)$ of the required number of patients (according to power analysis) were recruited for the first four participant groups that met in spring 2010. The same recruitment procedure was repeated to form four additional groups that met autumn 2010, containing the remaining 38 patients. Participants only learned about their treatment allocation at the beginning of the first group session.

\section{Conditions}

Participants randomized to the GI groups (experimental condition) attended two 1.5hour group sessions at the Van Praag Institute for complementary medicine in Utrecht in The Netherlands. The first session included group discussion, theoretical background of GI, distribution of a CD with three GI exercises (Van Praag Instituut, 2005), and instructions on how to use at least one exercise daily for 4 weeks. The group discussions were led by a specialized rheumatology nurse (T.K.), and the instructions on GI were given by a qualified trainer of the Van Praag Institute (M.B.). GI exercises on the CD had a duration varying between 18:48 and 28:36 minutes and contained relaxation techniques, music, positive imagery, and elements that were specifically designed for pain management, for example, the instruction "now imagine that you leave all the pain you experience at the beach post." After 4 weeks, the second group session took place consisting of group discussion (led by T.K.). Participants randomized to the attention control groups received two 1.5-hour group sessions at the Van Praag Institute with group discussion only (led by T.K.). Control groups did not receive any information or training in GI during this study. Like the GI condition, the second group session was held 4 weeks after the first group session. The quality of the intervention was controlled for by asking participants to fill out an evaluation questionnaire at the end of the second group session

\section{Measuring times}

In both conditions, measurements took place at three moments:

1. Pretest: just before the first group session;

2. Posttest: just before the second group session;

3. Follow-up: 6 weeks after the second group session.

Additionally, all participants were asked to complete a daily pain diary between the first and second group sessions.

\section{Measures}

Participants daily scored their subjective pain intensity on a $10 \mathrm{~cm}$ VAS that was included in the pain diary. The VAS ranged from no pain (0) to severe pain (10) and had to be scored from days 1 to 26. The VAS for pain is often used in clinical practice and research and has been shown to be a valid and reliable measure (Price et al., 1994). Patients were also asked to report in the diary on their medication use, care received, or other techniques used to reduce pain.

Functional status was measured with the Fibromyalgia Impact Questionnaire (FIQ). This instrument resembles the Health Assessment Questionnaire (HAQ) and the Arthritis Impact Measurement Scale (AIMS). The FIQ contains questions that follow 
Verkaik, R., Busch, M., Koeneman, T., Berg, R. van den, Spreeuwenberg, P., Francke, A.L. Guided imagery in people with fibromyalgia: A randomized controlled trial of effects on pain, functional status and self-efficacy. Journal of Health Psychology: 2014, 19(5), 678-688

directly from the HAQ and the AIMS and items that were used in earlier descriptive studies on FM (Burckhardt et al., 1991).

The FIQ consists of three parts. Part 1 contains 10 questions about activities involving major muscle groups. In part 2, questions are asked about the number of "good days" and the number of days missed from work the week before. Part 3 contains seven questions regarding the ability to work, pain, fatigue, morning stiffness, general stiffness, fear, and depression. The test-retest reliability of each item was measured over a period of a week (Burckhardt et al., 1991): The mean correlation for items regarding pain is $r=0.56$. The mean correlation for items regarding physical functioning is $r=0.95$. The correlation of the FIQ with subscales of the AIMS varies between 0.67 and 0.76 (Burckhardt et al., 1991).

Self-efficacy in dealing with pain was assessed using a subscale of the Chronic Pain Self-Efficacy Scale (CPSS), the subscale "self-efficacy for managing pain.” Items in this scale focus on the extent to which a person is confident that she or he can manage pain, regarding activities of daily living or sleep. Subscale scores range from 10 to 100 , with the higher scores indicating a higher level of self-efficacy. Reliability and validity of the CPSS were shown by Anderson et al. (1995).

At the first measuring time, background characteristics of the participants were also collected, such as age, sex, and date of the FM diagnosis. In addition, at the end of the second group session, participants were asked to complete a short evaluation questionnaire regarding their appreciation of the intervention. The questionnaire is based on the evaluation questionnaire by Borkovec and Nau (1972).

\section{Statistical methods}

\section{Daily pain.}

Multilevel repeated measures for continuous time with autocorrelated errors was used. Daily pain measurements are nested within individuals. The development over time is modeled using the serial day number. In the fixed part, this was modeled as a third-order polynomial, and this captures the development over time in the average daily pain score. This was done separately for the control and the experimental group. Based on these two developments over time, the hypothesis was tested that the development pattern over time differed between the two groups, and also daily estimated average pain scores were calculated for the two groups (with standard errors). Estimated average pain scores are corrected for baseline scores, medication use, and duration of the FM diagnosis. At the individual level, the intercept variance was allowed to vary linear with time (to allow for people in the same group to become more the same or more different over time). The autocorrelation between measurement occasions within individuals was controlled for using a design matrix (see Rasbash et al., 2009).

\section{Functional status and self-efficacy.}

For analyzing the effects on functional status and self-efficacy, multilevel repeated measures analysis was also performed using MLwiN software (Rasbash et al., 2000). The multilevel model took into account all available data of the paired samples of participants on three or two of the tests (pretests and posttests) as well as the unpaired premeasurement pretest data. The correlated paired measurements are controlled for by modeling the covariance between the measurements at the patients' level (Bryk and Raudenbusch, 1992; Goldstein, 1995). The multilevel model was applied to all but one participant for whom not all covariate data were complete. This 
Verkaik, R., Busch, M., Koeneman, T., Berg, R. van den, Spreeuwenberg, P., Francke, A.L. Guided imagery in people with fibromyalgia: A randomized controlled trial of effects on pain, functional status and self-efficacy. Journal of Health Psychology: 2014, 19(5), 678-688

case $(n=1)$ was excluded from the analyses. Data of participants with complete covariate data $(n=64)$ were analyzed using the intention-to-treat principle: all participants were analyzed according to group assignment. For all outcome measures on pretest, posttest, and follow-up, adjusted estimated means and standard errors were calculated for the experimental and control groups. Adjusted estimated means are the average scores corrected for the scores on the baseline measurement and other covariates (medication use and duration of the FM diagnosis). To compare differences from pretest to follow-up between the experimental and the control groups, $\chi^{2}(\mathrm{df}=1)$ were calculated. Differences were considered significant if $\chi^{2}$ was $\geq 3.84(\mathrm{p} \leq .05)$.

\section{RESULTS}

\section{Participants}

The sample consisted of 65 patients with FM, with a mean age of 47.4 years (SD = 11.4), aged 22-76 years. Only one male patient participated, and the others were female. Sixty-three percent of the participants were married or living together with a partner, and 68 percent were employed, most of them between 16 and 32 hours per week. The mean number of years since the diagnosis was 2.2 years $(\mathrm{SD}=1.8)$. Background characteristics of the participants in the experimental and control groups are presented in Table 1 . Analyses show that the experimental and control groups do not significantly differ on any of the background characteristics $(\mathrm{p} \geq .05)$.

In total, 70 patients met inclusion criteria and signed the informed consent form. Five of them dropped out before the first group session: one in the experimental group because of being ill and four in the control group due to illness $(n=3)$ and because of already using the CD with GI exercises. Two participants in the experimental group dropped out before the second group session because the exercises and attending the group sessions took too much energy. Six participants (two in experimental group and four in control group) did not attend the second group session due to illness $(n=3)$ or unforeseen circumstances $(n=3)$ and did not fill out the questionnaire at posttest. Another four participants (two in the experimental condition and two in the control condition) did not return the questionnaire that was mailed to them at the follow-up measurement time. Figure 2 shows the patient flow throughout the study.

The collected data of the 12 participants that were missing at posttest and/or followup could still be used in the multilevel analyses according to the intention-to-treat principle. Analyses show no differences in background characteristics between participants who were involved until the end of the study and participants who were not $(\mathrm{p} \geq .05)$.

The same eight participants who had not completed the questionnaires on functional status and self-efficacy at posttest had not completed the pain diaries. In total, 57 pain diaries could be analyzed.

\section{Pain}

Figure 3 shows the average VAS pain scores from days 1 to 26 in the experimental and control groups. Table 2 contains the exact scores and 95 percent confidence intervals.

No significant effects on pain intensity could be assessed. Neither the experimental group nor the control group shows a significant reduction or increase of pain 
Verkaik, R., Busch, M., Koeneman, T., Berg, R. van den, Spreeuwenberg, P., Francke, A.L. Guided imagery in people with fibromyalgia: A randomized controlled trial of effects on pain, functional status and self-efficacy. Journal of Health Psychology: 2014, 19(5), 678-688

intensity from days 1 to 26, not even within individual participants. Also, no significant differences between the two groups could be found $\left(\chi^{2}=0.02\right)$. These findings indicate that the use of GI has not resulted in the expected reduction of pain intensity.

\section{Functional status}

Functional status as measured by the FIQ at pretest, posttest, and follow-up is also presented in Table 3. Table 3 also shows $\chi 2$ values that indicate whether measurements in the experimental and control groups differ significantly $(\mathrm{p} \leq .05)$.

\section{[TABLE 1]}

No significant treatment effect was obtained for functional status. In the experimental group, functional status on a scale from 0 to 100 first improves from 53.7 $( \pm 2.70)$ to $49.0( \pm 2.50)$ and then regresses back to $54.2( \pm 2.58)$ at follow-up. In the control group, functional status improves from $56.4( \pm 2.03)$ to $52.8( \pm 2.21)$ at posttest and remains at the same level with $53.0( \pm 2.46)$ at follow-up.

\section{Self-efficacy}

Self-efficacy as assessed with the subscale "self-efficacy for managing pain" from the CPSS did not show significant improvements either (see also Table 3). In the experimental group, self-efficacy (0-100) first improves from $52.4( \pm 2.82)$ to 56.3 $( \pm 3.57)$ and then regresses to $54.3( \pm 3.08)$ at follow-up. In the control group, selfefficacy for managing pain regresses from $51.9( \pm 3.13)$ to $49.5( \pm 2.29)$ at posttest and then improves to $52.8( \pm 2.82)$ at follow-up. The groups do not differ significantly.

\section{[FIGURE 2]}

\section{DISCUSSION}

\section{Outcomes}

No effects of GI could be established on pain intensity of patients with FM.

However, it must be taken into account that we only measured general pain intensity at the end of each day and not during the GI exercises or directly afterward, which is a limitation of the current study.

In the first study they conducted, Fors et al. (2000) showed that GI could indeed have positive effects on pain experienced during the exercises. In the second study, Fors et al. (2002) also showed effects on generally experienced pain using a daily VAS comparable with the pain diary scores used in our study. An explanation for the fact that we did not find effects on general pain whereas Fors et al. (2002) did might be found in the specific content of the GI exercises. Fors et al. only used positive imagery and did not refer to pain or other negative aspects, while our imagery exercises did. The fact that the content of the exercises of Menzies et al. (2006) 
Verkaik, R., Busch, M., Koeneman, T., Berg, R. van den, Spreeuwenberg, P., Francke, A.L. Guided imagery in people with fibromyalgia: A randomized controlled trial of effects on pain, functional status and self-efficacy. Journal of Health Psychology: 2014, 19(5), 678-688

partly used positive imagery (weeks 1-4) and partly also focused on experienced pain (weeks 5 and 6) might explain why their effects on pain were not large enough to reach significance, but were sufficiently clinically relevant to have effects on selfefficacy and functional status.

In addition to the differences in content of the GI exercises, there were some other differences that might play a role in the study by Menzies (2006) being effective in enhancing self-efficacy and functional status:

1. The intervention period in the study by Menzies lasted 2 weeks longer, namely 6 weeks instead of 4 weeks. In addition, during the follow-up period of 4 weeks, the participants in Menzies' study were still asked to engage in GI at least once daily, while in our study participants were free to do the exercises during this period or not; 2. In the study by Menzies, not only self-efficacy in managing pain was assessed, but self-efficacy in managing other symptoms was also assessed. Their score on the CPSS contains the summed scores on both subscales;

3. The participants in the study by Menzies were recruited from physicians' offices and clinics, while most of our participants were recruited via the FM patient organization and notices in local newspapers. It is possible that the participants in the study by Menzies had less experience with complementary and other

\section{[FIGURE 3] [TABLE 2] [TABLE 3]}

interventions than the participants in our study, which enlarges the chance that their self-efficacy and functional status were enhanced more easily.

Although no effects of GI on pain, self-efficacy, or functional status could be established, 85 percent of the experimental group would recommend the GI group sessions to family or friends and 96 percent found the GI applicable in daily life.

\section{Directions for practice and future research}

The above-mentioned differences could explain (part) of the lack of effects in our study on daily pain, functional status, and self-efficacy and may give some insight into important features that should not be missed if we want GI to be effective. First, GI exercises might be more effective if they do not directly refer to experienced pain. The studies by Fors et al. $(2000,2002)$ support this recommendation, although they did not examine the effects on self-efficacy and functional status. More research is needed on this subject. Second, the use of GI might need support by trainers/caregivers for a longer period to be effective in enhancing self-efficacy and functional status and probably also pain. Some participants in our experimental group even suggested extending the support to a year. Third, as many participants in our study suggested, chronic pain should not only be the main focus but also other symptoms like fatigue and sleep disturbance. According to them, pain is something they have learned to cope with to some extent, but other symptoms of FM may hamper their functioning in daily life more. Moreover, the American College of Rheumatology recently published new preliminary diagnostic criteria for FM and measurement of symptom severity (Wolfe et al., 2010), removing the focus from chronic pain to cognitive problems, unrefreshed sleep, fatigue, and somatic symptoms. 
Verkaik, R., Busch, M., Koeneman, T., Berg, R. van den, Spreeuwenberg, P., Francke, A.L. Guided imagery in people with fibromyalgia: A randomized controlled trial of effects on pain, functional status and self-efficacy. Journal of Health Psychology: 2014, 19(5), 678-688

\section{FUNDING}

This study was financially supported by Fonds NutsOhra, Amsterdam, The Netherlands.

\section{REFERENCES}

Ablin J, Neumann L and Buskila D (2008) Pathogenesis of fibromyalgia—A review. Joint Bone Spine 75: 273-279.

Anderson KO, Dowds BN, Pelletz RE, et al. (1995) Development and initial validation of a scale to measure self-efficacy beliefs in patients with chronic pain. Pain 63(1): 77-84.

Borkovec TD and Nau SD (1972) Credibility of analogue therapy rationales. Journal of Behavior Therapy and Experimental Psychiatry 3: 257-260.

Bradley LA (2009) Pathophysiology of fibromyalgia. American Journal of Medicine 122(Suppl. 12A): S22-S30.

Bradley LA and McKendree-Smith NL (2002) Central nervous system mechanisms of pain in fibromyalgia and other musculoskeletal disorders: Behavioral and psychologic treatment approaches. Current Opinion in Rheumatology 14: 45-51.

Bryk AS and Raudenbusch SW (1992) Hierarchical Linear Models: Applications and Datamanagement Methods. Newbury Park, CA: SAGE.

Burckhardt CS, Clark SR and Bennet RM (1991) The Fibromyalgia Impact Questionnaire: Development and validation. The Journal of Rheumatology 91(18): 728-733.

Buskila D, Sarzi-Puttini P and Ablin JN (2007) The genetics of fibromyalgia syndrome. Pharmacogenomics 8: 67-74.

Cohen J (1988) Statistical Power Analysis for the Behavioral Sciences (2nd edn). Hillsdale, $\mathrm{NJ}$ : Lawrence Erlbaum Association, Inc.

Eller LS (1999) Guided imagery interventions for symptom management. Annual Review of Nursing Research 17: 57-84.

Fors EA and Götestam KG (2000) Patient education, guided imagery, and pain related talk in fibromyalgia coping. European Journal of Psychiatry 14: 233-240.

Fors EA, Sexton H and Götestam KG (2002) The effect of guided imagery and amitriptyline on daily fibromyalgia pain: A prospective, randomized, controlled trial. Journal of Psychiatric Research 36: 179-187.

Goldstein H (1995) Multilevel Statistical Models. New York: Halsted Press.

Lewith G, Kenyon J and Lewis P (1996) Complementary Medicine: An Integrated Approach. Oxford: Oxford University Press.

McCarberg BH (2012) Clinical overview of fibromyalgia. American Journal of Therapeutics 19(5): 357-368.

Menzies V and Taylor AG (2004) The idea of imagination: A concept analysis of imagery. Advances in Mind-Body Medicine 20: 4-10.

Menzies V, Taylor AG and Bourguignon C (2006) Effects of guided imagery on outcomes of pain, functional status, and self-efficacy in persons diagnosed with fibromyalgia. Journal of Alternative and Complementary Medicine 12: 23-30.

Nielsen LA and Henriksson KG (2007) Pathophysiological mechanisms in chronic musculoskeletal pain (fibromyalgia): The role of central and peripheral sensitization and pain disinhibition. Best Practice \& Research. Clinical Rheumatology 21: 465-480.

Price DD, Bush FM, Long S, et al. (1994) A comparison of pain measurement characteristics of mechanical visual analogue and simple numerical rating scales. Pain 56(2): 217-226.

Rasbash J, Browne W and Healy M (2000) MLwiN (version 1.10). London: Multilevel Models Project Institute of Education.

Rasbash J, Charlton C, Jones K, et al. (2009) Manual Supplement for MLwiN Version 2.14. Centre for Multilevel Modelling, University of Bristol. Bristol, UK.

Stahl SM (2009) Fibromyalgia-pathways and neurotransmitters. Human Psychopharmacology: Clinical and Experimental 24(Suppl. 1): S11-S17.

Staud R (2006) Biology and therapy of fibromyalgia: Pain in fibromyalgia syndrome. Arthritis Research \& Therapy 8: 208.

Van Praag Institute (2005) Gezonde Verbeelding. Geleide visualisatie by pyn. Utrecht The Netherlands: Elsevier Gezondheidszorg 
Verkaik, R., Busch, M., Koeneman, T., Berg, R. van den, Spreeuwenberg, P., Francke, A.L. Guided imagery in people with fibromyalgia: A randomized controlled trial of effects on pain, functional status and self-efficacy. Journal of Health Psychology: 2014, 19(5), 678-688

Williams DA and Clauw DJ (2009) Understanding fibromyalgia: Lessons from the broader pain research community. The Journal of Pain 10: 777-791.

Wolfe F, Clauw DJ, Fitzcharles MA, et al. (2010) The American College of Rheumatology preliminary diagnostic criteria for fibromyalgia and measurement of symptom severity. Arthritis Care \& Research 62(5): 600-610. 
Verkaik, R., Busch, M., Koeneman, T., Berg, R. van den, Spreeuwenberg, P., Francke, A.L. Guided imagery in people with fibromyalgia: A randomized controlled trial of effects on pain, functional status and self-efficacy. Journal of Health Psychology: 2014, 19(5), 678-688

\section{TABLES AND FIGURES}

Figure 1. model of the neuromatrix

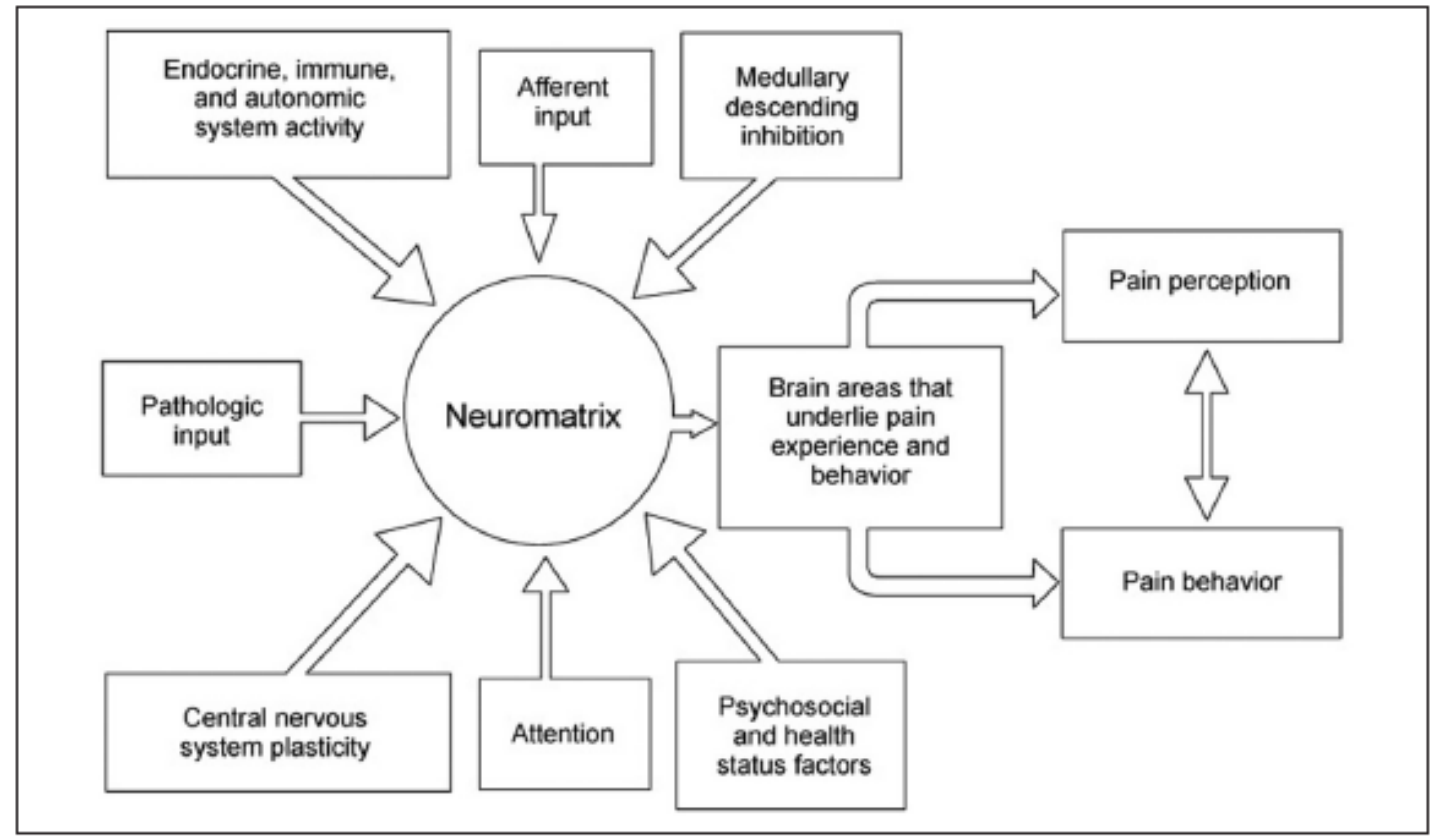


Verkaik, R., Busch, M., Koeneman, T., Berg, R. van den, Spreeuwenberg, P., Francke, A.L. Guided imagery in people with fibromyalgia: A randomized controlled trial of effects on pain functional status and self-efficacy. Journal of Health Psychology: 2014, 19(5), 678-688

Table I. Participant background characteristics $(n=65)$

\begin{tabular}{|c|c|c|}
\hline & Experimental group $(n=32)$ & Control group $(n=33)$ \\
\hline Age, years (mean $\pm S D$ ) & $47.3 \pm 10.3$ & $47.7 \pm 12.5$ \\
\hline Range & $24-68$ & $22-76$ \\
\hline Sex female, $n(\%)$ & $32(100)$ & $32(97)$ \\
\hline \multicolumn{3}{|l|}{ Marital status } \\
\hline Married, $n$ (\%) & $16(50)$ & $15(46)$ \\
\hline $\begin{array}{l}\text { Living together with partner, } n \\
\text { (\%) }\end{array}$ & $5(16)$ & $5(15)$ \\
\hline Divorced, $n$ (\%) & $5(16)$ & $4(12)$ \\
\hline $\begin{array}{l}\text { Unmarried and not living to- } \\
\text { gether, } n(\%)\end{array}$ & $5(16)$ & $8(24)$ \\
\hline Other & I (3) & - \\
\hline Missing & - & I (3) \\
\hline \multicolumn{3}{|l|}{ Educational level } \\
\hline Lower vocational & $4(13)$ & $3(9)$ \\
\hline Intermediate vocational & $18(56)$ & $16(49)$ \\
\hline Higher vocational & $10(31)$ & $12(36)$ \\
\hline Other & - & I (3) \\
\hline Missing & - & I (3) \\
\hline \multicolumn{3}{|l|}{ Employment } \\
\hline No & II (35) & $10(30)$ \\
\hline Less than 16 hours weekly & $3(9)$ & $9(28)$ \\
\hline $\begin{array}{l}\text { Between } 16 \text { and } 32 \text { hours } \\
\text { weekly }\end{array}$ & $14(44)$ & $10(30)$ \\
\hline $\begin{array}{l}\text { Between } 33 \text { and } 40 \text { hours } \\
\text { weekly }\end{array}$ & $3(9)$ & $3(9)$ \\
\hline More than 40 hours weekly & - & I (3) \\
\hline Missing & I (3) & - \\
\hline \multicolumn{3}{|l|}{ Years since diagnosis } \\
\hline $0-1$ year & $17(53)$ & $12(37)$ \\
\hline $2-4$ years & $12(38)$ & $16(48)$ \\
\hline $\begin{array}{l}5-6 \text { years } \\
\text { Missing }\end{array}$ & $3(9)$ & $\begin{array}{l}4(12) \\
1(3)\end{array}$ \\
\hline
\end{tabular}


Verkaik, R., Busch, M., Koeneman, T., Berg, R. van den, Spreeuwenberg, P., Francke, A.L. Guided imagery in people with fibromyalgia: A randomized controlled trial of effects on pain, functional status and self-efficacy. Journal of Health Psychology: 2014, 19(5), 678-688

Figure 2 participant flow

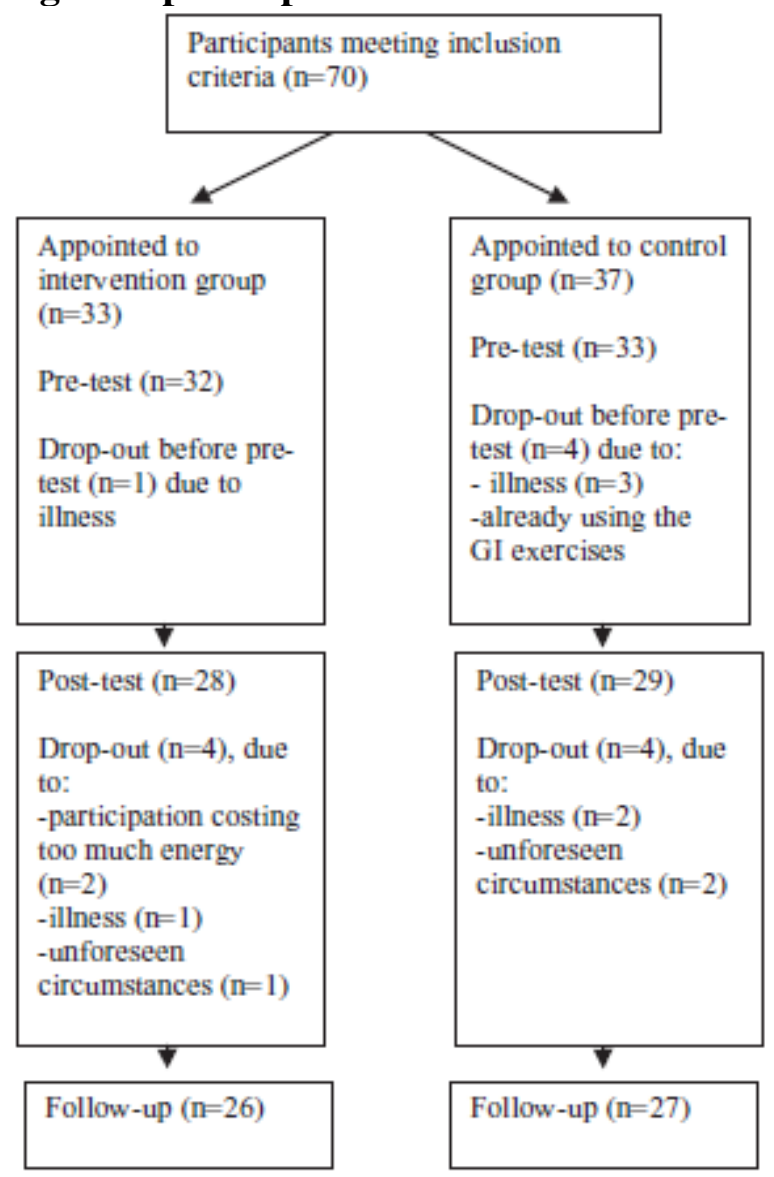

Figure 3. VAS pain diary scores from days 1 to 26 in the experimental and control groups.

VAS=Visual Analogue Scale

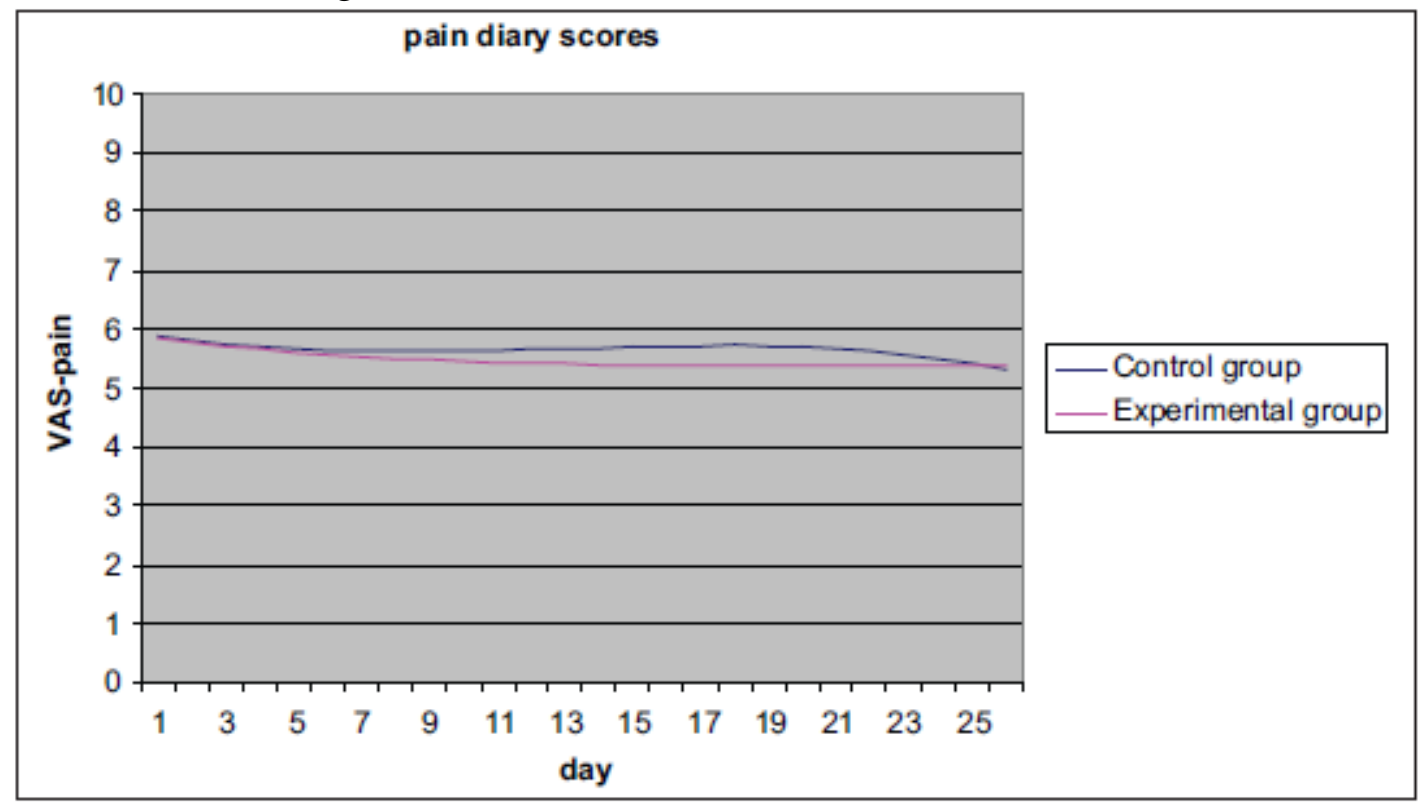


Verkaik, R., Busch, M., Koeneman, T., Berg, R. van den, Spreeuwenberg, P., Francke, A.L. Guided imagery in people with fibromyalgia: A randomized controlled trial of effects on

Table 2. Mean VAS pain scores from days I to 26 with 95 percent confidence intervals

\begin{tabular}{lllll}
\hline Day & Control group & $\begin{array}{l}95 \% \text { Confidence } \\
\text { interval }\end{array}$ & Experimental group & $\begin{array}{l}95 \% \text { Confidence } \\
\text { interval }\end{array}$ \\
\hline 1 & 5.88 & $5.31-6.32$ & 5.84 & $5.04-6.58$ \\
2 & 5.81 & $5.31-6.22$ & 5.78 & $5.02-6.49$ \\
3 & 5.75 & $5.29-6.15$ & 5.72 & $4.99-6.42$ \\
4 & 5.70 & $5.27-6.11$ & 5.67 & $4.95-6.37$ \\
5 & 5.67 & $5.25-6.08$ & 5.62 & $4.91-6.32$ \\
6 & 5.65 & $5.24-6.07$ & 5.58 & $4.88-6.28$ \\
7 & 5.63 & $5.23-6.06$ & 5.54 & $4.85-6.24$ \\
8 & 5.63 & $5.23-6.06$ & 5.51 & $4.82-6.21$ \\
9 & 5.63 & $5.23-6.06$ & 5.48 & $4.80-6.18$ \\
10 & 5.63 & $5.23-6.07$ & 5.46 & $4.78-6.15$ \\
11 & 5.64 & $5.24-6.08$ & 5.44 & $4.76-6.13$ \\
12 & 5.66 & $5.25-6.09$ & 5.42 & $4.74-6.11$ \\
13 & 5.67 & $5.26-6.11$ & 5.41 & $4.72-6.10$ \\
14 & 5.69 & $5.27-6.13$ & 5.40 & $4.72-6.09$ \\
15 & 5.70 & $5.27-6.14$ & 5.39 & $4.71-6.10$ \\
16 & 5.72 & $5.27-6.16$ & 5.38 & $4.69-6.07$ \\
17 & 5.72 & $5.27-6.17$ & 5.38 & $4.68-6.07$ \\
18 & 5.73 & $5.26-6.18$ & 5.38 & $4.68-6.07$ \\
19 & 5.73 & $5.24-6.18$ & 5.38 & $4.67-6.07$ \\
20 & 5.72 & $5.22-6.18$ & 5.38 & $4.66-6.08$ \\
21 & 5.67 & $5.15-6.14$ & 5.38 & $4.66-6.09$ \\
22 & 5.63 & $5.11-6.11$ & 5.38 & $4.65-6.09$ \\
\hline
\end{tabular}

(Continued)

Table 2. (Continued)

\begin{tabular}{lllll}
\hline Day & Control group & $\begin{array}{l}95 \% \text { Confidence } \\
\text { interval }\end{array}$ & Experimental group & $\begin{array}{l}95 \% \text { Confidence } \\
\text { interval }\end{array}$ \\
\hline 23 & 5.58 & $5.04-6.07$ & 5.38 & $4.65-6.10$ \\
24 & 5.51 & $4.96-6.02$ & 5.38 & $4.63-6.12$ \\
25 & 5.43 & $4.85-5.98$ & 5.38 & $4.61-6.14$ \\
26 & 5.33 & $4.71-5.93$ & 5.37 & $4.57-6.18$ \\
\hline
\end{tabular}

Table 3. Differences over the measurement times between experimental and control groups

\begin{tabular}{|c|c|c|c|c|c|c|c|}
\hline & \multirow{2}{*}{\multicolumn{2}{|c|}{$\begin{array}{l}\text { Pretest } \\
\text { Mean }( \pm S E)\end{array}$}} & \multirow{2}{*}{\multicolumn{2}{|c|}{$\begin{array}{l}\text { Posttest } \\
\text { Mean ( } \pm \text { SE) }\end{array}$}} & \multirow{2}{*}{\multicolumn{2}{|c|}{$\begin{array}{l}\text { Follow-up } \\
\text { Mean }( \pm \text { SE) }\end{array}$}} & \multirow[t]{3}{*}{$\chi^{2}$} \\
\hline & & & & & & & \\
\hline & $\begin{array}{l}\text { Experimental } \\
\text { group }\end{array}$ & $\begin{array}{l}\text { Control } \\
\text { group }\end{array}$ & $\begin{array}{l}\text { Experimental } \\
\text { group }\end{array}$ & $\begin{array}{l}\text { Control } \\
\text { group }\end{array}$ & $\begin{array}{l}\text { Experimental } \\
\text { group }\end{array}$ & $\begin{array}{l}\text { Control } \\
\text { group }\end{array}$ & \\
\hline $\begin{array}{l}\text { Functional status: } \\
\text { FIQ }(0-100)\end{array}$ & $53.7(2.7)$ & $56.4(2.03)$ & $49.0(2.50)$ & $52.8(2.21)$ & $54.23(2.6)$ & $53.0(2.46)$ & 1.55 \\
\hline $\begin{array}{l}\text { Self-efficacy: } \\
\text { CPSS }(0-100)\end{array}$ & $52.4(2.82)$ & $51.9(3.13)$ & $56.3(3.57)$ & 49.5 (2.29) & $54.3(3.08)$ & $52.8(2.87)$ & 0.08 \\
\hline
\end{tabular}

SE: standard error; FIQ: Fibromyalgia Impact Questionnaire; CPSS: Chronic Pain Self-Efficacy Scale.

Italicized score behind the measures indicates the most favorable score for the scale. 